See Article page 1965.

\section{Commentary: Transoral stapling for Zenker diverticulectomy: There is no substitute for experience}

\author{
Siva Raja, MD, PhD, FACS
}

Zenker diverticulum is a rare condition among benign esophageal disorders. Since its introduction more than 60 years ago, myotomy and diverticulectomy have been the mainstay of therapy for patients with this condition. ${ }^{1}$ Although open surgery has been the gold standard, transoral stapling for Zenker diverticulectomy has now been around long enough to challenge conventional open therapies.

Levy and colleagues ${ }^{2}$ report their experience over nearly 20 years in 151 patients. The results show excellent improvement in dysphagia postoperatively compared with the preoperative symptom score and low morbidity. The granularity of their institutional database also allows them to develop selection criteria, identify failures, and describe the natural history of patients with treated Zenker diverticulectomy. Along with excellent results, the authors provide numerous technical pearls garnered from their experience that should allow us to benefit from their experience.

With all retrospective studies, there are limitations to the conclusions. With 151 patients, the number of variables that predict failure are limited. In this case, the relatively low rate of failure among the 151 patients did not allow for the identification of any risk factors for failure. However, the size of diverticula seemed to be larger $(4.41 \mathrm{~cm})$ than the median value in this cohort $(3 \mathrm{~cm})$. Additionally, failure is a time-dependent phenomenon. As such, the statement that the failure rate is $5.3 \%$ in this study cohort does not reflect the loss to follow-up with increasing time. Based on their curves for freedom from failure, they suggest a

\footnotetext{
From the Department of Thoracic and Cardiovascular Surgery, Heart and Vascular Institute, Cleveland Clinic Foundation, Cleveland, Ohio.

Disclosures: The author reported no conflicts of interest.

The Journal policy requires editors and reviewers to disclose conflicts of interest and to decline handling or reviewing manuscripts for which they may have a conflict of interest. The editors and reviewers of this article have no conflicts of interest.

Received for publication Jan 6, 2021; revisions received Jan 6, 2021; accepted for publication Jan 6, 2021; available ahead of print Jan 20, 2021.

Address for reprints: Siva Raja, MD, PhD, FACS, Department of Thoracic and Cardiovascular Surgery, Heart and Vascular Institute, Cleveland Clinic Foundation, J41, 9500 Euclid Ave, Cleveland, OH 44195 (E-mail: rajas@ccf.org).

J Thorac Cardiovasc Surg 2022;163:1975

$0022-5223 / \$ 36.00$

Copyright (c) 2021 by The American Association for Thoracic Surgery

https://doi.org/10.1016/j.jtcvs.2021.01.026
}

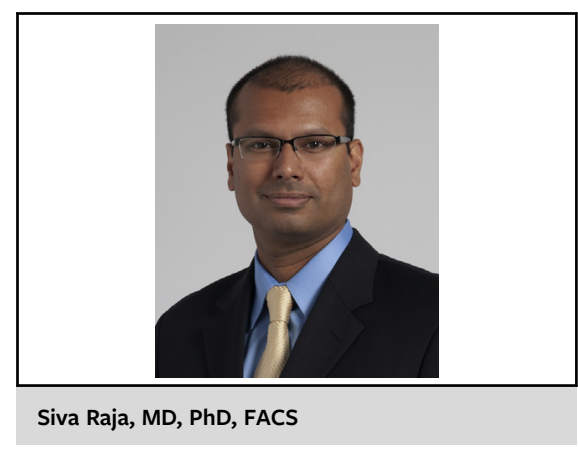

CENTRAL MESSAGE

Transoral stapling for Zenker

diverticulum has good results in

experienced centers.

failure rate just under $10 \%$ at 6 years. Finally, their outcomes are certainly in line with other open and endoscopic series cited in their article-most of which had similar outcomes. However, in the absence of a control group, it is difficult to state if this technique is indeed superior to conventional cervical approach in the authors' hands.

This series emphasizes the outcomes in the context of a thoracic surgical service. Although most thoracic surgeons are required to have some training in esophageal surgery, many as a matter of practice do not perform any significant esophageal surgery in their daily practice. This is especially true of highly technical but low-volume surgeries such as those used to treat Zenker diverticulum. Most of us would say that the authors' excellent outcomes are indeed due to their extensive experience in esophageal surgery irrespective of their training paradigm or Board certification. This need for experience is important for 2 reasons. First, all procedures have a learning curve. The authors themselves note that the majority of their failure was during the first half of their experience. They provide excellent technical tips that one can suspect came from challenging cases. Second, techniques and technology change. In this case, we finally have good long-term data on transoral stapling to determine its relative effectiveness compared with conventional approaches. Even if this technique can be considered equivalent, we have per oral endoscopic myotomy for Zenker diverticulum (Z-POEM) that is being routinely offered in some institutions, including ours. ${ }^{3}$ My suspicion is that by the time we determine whether Z-POEM is safe and effective, we may likely have flexible endoscopic staplers that 
will question the need for Z-POEM. Because this is a rare condition, we need to have a general body of experience in the field and a good understanding of the pathophysiology of the underlying condition being treated irrespective of the specific technique. Solutions change (usually for the better) but the problem stays the same. As such, for optimal outcomes, experience matters!

\section{References}

1. Ellis FH Jr, Schlegel JF, Lynch VP, Payne WS. Cricopharyngeal myotomy for pharyngo-esophageal diverticulum. Ann Surg. 1969;170:340-9.

2. Levy RM, Luketich JD, Brynien D, Mpamaugo C, Shende MR, Gooding WE, et al. Transoral endoscopic repair of Zenker diverticulum by a thoracic surgical service. J Thorac Cardiovasc Surg. 2022;163:1965-74.e1.

3. Brewer Gutierrez OI, Ichkhanian Y, Spadaccini M, Vosoughi K, Repici A, Khashab MA. Zenker's diverticulum per-oral endoscopic myotomy techniques: changing paradigms. Gastroenterology. 2019;156:2134-5.
See Article page 1965 .

\section{Commentary: Transoral endoscopic repair of Zenker's diverticulum by a thoracic surgical service}

\author{
Xavier Benoit D'Journo, MD, $\mathrm{PhD}$, \\ Alex Fourdrain, MD, and David Boulate, MD, PhD
}

Despite the lack of consensus on the treatment of Zenker's diverticulum (ZD), open surgery is being progressively replaced by endoluminal endoscopic surgery, which appears to allow for a lower rate of complications and lower hospital costs and provides satisfactory long-term outcomes with the possibility of redo endoluminal treatment. ${ }^{1,2}$

In this issue of the Journal, Levy and colleagues ${ }^{3}$ provide early and late functional results after transoral stapling repair based on a consecutive series of $151 \mathrm{ZD}$ patients. Based on a single-institution database, the authors report a low rate of conversion $(10 \%)$, a low rate of complications $(4 \%)$, and a median hospital stay of 2 days. With a median follow-up of 52 months, the estimated probability of freedom from failure was $96 \%$ at 2 years and $92 \%$ at 5 years.

Although most published series on endoscopic repair have been reported by otolaryngologists and gastroenterologists, the authors point out that endoluminal repair can be

\footnotetext{
From the Department of Thoracic Surgery, CHU Nord, Aix-Marseille University, CNRS, INSERM, CRCM, AP-HM, Marseille, France.

Disclosures: The authors reported no conflicts of interest.

The Journal policy requires editors and reviewers to disclose conflicts of interest and to decline handling or reviewing manuscripts for which they may have a conflict of interest. The editors and reviewers of this article have no conflicts of interest.

Received for publication Jan 14, 2021; revisions received Jan 14, 2021; accepted for publication Jan 14, 2021; available ahead of print Jan 20, 2021.

Address for reprints: Xavier Benoit D'Journo, MD, PhD, Department of Thoracic Surgery, Aix-Marseille University, North Hospital, Chemin des Bourrely, 13915 Marseille, France (E-mail: xavier.djourno@ap-hm.fr).

J Thorac Cardiovasc Surg 2022;163:1976-7

$0022-5223 / \$ 36.00$

Copyright (c) 2021 by The American Association for Thoracic Surgery

https://doi.org/10.1016/j.jtcvs.2021.01.050
}

Check for updates

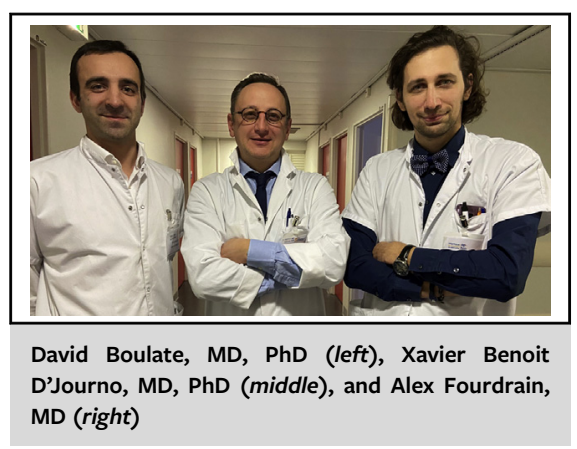

CENTRAL MESSAGE

Modern treatment of Zenker's

diverticulum includes endolumi-

nal surgery. This study confirms

that experienced thoracic sur-

geons are appropriately profi-

cient in performing such

emerging techniques.

performed in a thoracic surgery department. This raises the question of placing endoluminal repair in the core competencies of thoracic surgeons. Even if UPMC staff surgeons are well known for their expertise in esophageal surgery, many thoracic surgeons worldwide do not routinely perform esophageal surgery. However, esophageal surgery is included in the scope of several national surgical thoracic societies in North America, Asia, and Europe. Acquisition of competencies in esophageal procedures is required to graduate from a complete training program in many of these societies. The available data confirm that in experienced centers, thoracic surgeons have appropriate proficiency in performing endoluminal surgery.

Levy and colleagues have reported only results of transoral stapling whereas peroral endoscopic myotomy (POEM) with 